\title{
Open access - reasons to be cheerful: a reply to Agrawal
}

\section{Stephen Curry}

Department of Life Sciences, Sir Ernst Chain Building, Imperial College, Exhibition Road, London SW7 2AZ, United Kingdom. Email: s.curry@imperial.ac.uk

Anurag Agrawal's recent letter on open access publishing [1] raises an important topic that many researchers may have found difficult to engage with, not least because its myriad complexities are frequently enveloped in strong cross-currents of opinion. Agrawal is concerned that some scientists might still be rather uncritical of the accelerating open-access bandwagon and rightly highlights some of the possible pitfalls.

However, while it is important to be aware of the risks of open access, Agrawal was more pessimistic in his assessment than is warranted by the evidence and, in my view, paid insufficient attention to the possible benefits. Open access is as much a technological movement as an ideological one and has many positive aspects (see http://bit.ly/1lhPoIZ for Peter Suber's useful overview). It has arisen because the internet has completely changed the ways we can disseminate information, generate and analyze huge data sets, and interact within and beyond the research community. That transformation can be seen in the revamped operations of traditional publishers but has also stimulated an impulse to be more responsive - through open access - not just to the needs of authors, but to a wider range of stakeholders including funders, taxpayers, and various other forms of the 'public', such as activists, charities and democratic representatives.

Agrawal rightly identifies conflicts of interest as a potential difficulty for open access publishing models funded by author payment of article processing charges (APCs). The emergence of predatory open access journals has been problematic, but is often over-stated. It remains the case that most open access papers are published in reputable venues [2] - my rule of thumb is to publish in open access titles that I read. Nevertheless, conflicts of interest arising from APCs can and should be tackled through clear separation of publishing decisions from author payments, and through stronger, more visible monitoring by the Open Access Scholarly Publishers Association (OASPA) and the Directory of Open Access Journals (DOAJ).

Moreover, one should not forget that conflicts of interest may also arise at traditional journals, through payment of page charges or fees for colour figures or simply because of the need to attract sufficient content to justify subscriptions. Because many subscription journals are sold to university libraries as part of large bundles, there may not always be the level of scrutiny by readers that is needed to assure the quality of individual titles.

Agrawal is also correct to warn that some open access titles may not offer much in the way of copy-editing or services to improve illustrations. However, again this consideration applies more widely. Authors should come to regard publishing as a facility and consider the quality of the services offered by different titles, whether they be ease of the submission process, copy-editing, or the speed and rigor of peer review. Journal league tables ranking service performance in these areas could help authors to make better-informed choices.

Agrawal's contention that open access publication does not offer a citation advantage is based on a single study and is inconsistent with the weight of evidence. In 2010 a systematic review by Alma Swan found that twenty-seven of thirty-one different studies reported a citation advantage (http://eprints.soton.ac.uk/268516/), a conclusion that makes sense given the increased availability provided by open access. To further support informed choices, it will be important to continue to monitor these trends.

Finally Agrawal raises the thorny question of impact factors, inferring — not unreasonably — that they remain a major consideration for many authors. Though regretting the corrosive influence of impact factors on research careers, he concludes that deviation from community norms is likely to be too risky, especially for junior scientists.

That is a fair assessment of the reality on the ground but it is a reality that we must challenge. Technological changes are helping us to re-think how best to disseminate research information, but the transition is also an opportunity to reconsider old habits of assessment. Peter Lawrence and Ron Vale, among others, have written eloquently on what can be done to improve methods of evaluation that focus on the scientist rather than on the name of the journal in which they have published $[3,4]$. Some of these ideas are now being put into action through the San Francisco Declaration on Research Assessment (http://am.ascb.org/dora/), which has been signed by growing numbers of individuals and institutions. It will take leadership and sustained effort, especially from senior scientists, funders and university chiefs, to effect real change. Dissolving the over-reliance of assessment on journal impact factors is vital if we are to level the playing field and energize the open access innovations that are slowly transforming the publishing landscape. If more of us can join in the discussions needed to shape that future, we will arrive all the sooner at the publishing system we want for the 21 st Century.

\section{References}

1 Agrawal, A.A. (2014) Four more reasons to be skeptical of open-access publishing. Trends Plant Sci. (in press)

2 Solomon, D.J. and Björk, B.-C. (2012) A study of open access journals using article processing charges. J. Assoc. Inf. Sci. Technol. 63, 1485-1495

3 Lawrence, P.A. (2007) The mismeasurement of science. Curr. Biol. 17, R583-R585

4 Vale, R.D. (2012) Evaluating how we evaluate. Mol. Biol. Cell 23, 3285-3289 